\title{
Birth weight as a predictor of breast cancer: a case-control study in Norway
}

\section{LJ Vatten*,1, BO Mæhle², TI Lund Nilsen', S Tretli',3, C-c Hsieh, ${ }^{4,5}$ D Trichopoulos ${ }^{4}$ and SO Stuver ${ }^{4}$}

'Department of Community Medicine and General Practice, The Norwegian University of Science and Technology, N-7489 Trondheim, Norway; ${ }^{2}$ Department of Pathology, University of Bergen, Norway; ${ }^{3}$ The Nonwegian Cancer Registry, Oslo, Norway; ${ }^{4}$ Department of Epidemiology and Center for Cancer

Prevention, Harvard School of Public Health, Boston, Massachusetts, USA; ${ }^{5}$ University of Massachusetts Cancer Center, Worcester, Massachusetts, USA

The hypothesis that birth weight is positively associated with adult risk of breast cancer implies that factors related to intrauterine growth may be important for the development of this malignancy. Using stored birth records from the two main hospitals in Trondheim and Bergen, Norway, we collected information on birth weight, birth length and placenta weight among 373 women who developed breast cancer. From the same archives, we selected as controls I I 50 women of identical age as the cases without a history of breast cancer. Information on age at first birth and parity were collected from the Central Person Registry in Norway. Based on conditional logistic regression analysis, breast cancer risk was positively associated with birth weight and with birth length ( $P$ for trend=0.02). Birth weights in the highest quartile (3730 g or more) were associated with 40\% higher risk (odds ratio, 1.4, 95\% confidence interval, 1.1 - I.9) of breast cancer compared to birth weights in the lowest quartile (less than $3090 \mathrm{~g}$ ). For birth length, the odds ratio for women who were $51.5 \mathrm{~cm}$ or more (highest quartile) was 1.3 (95\% confidence interval, 1.0-1.8) compared to being less than $50 \mathrm{~cm}$ (lowest quartile) at birth. Adjustment for age at first birth and parity did not change these estimates. Placenta weight was not associated with breast cancer risk. This study provides strong evidence that intrauterine factors may influence future risk of breast cancer. A common feature of such factors would be their ability to stimulate foetal growth and, simultaneously, to influence intrauterine development of the mammary gland.

British Journal of Cancer (2002) 86, 89-91. DOI: 10.1038/sj/bjc/66000I I www.bjcancer.com

(C) 2002 The Cancer Research Campaign

Keywords: breast cancer; birth weight; birth length; placenta weight

The hypothesis that breast cancer may originate in utero implies that factors related to intrauterine growth in the female offspring increase adult risk of breast cancer (Trichopoulos, 1990). It has been suggested that prenatal stimulation of growth may increase the number of cells and the rate of cell division in breast tissue and, thereby, increase the risk of malignant transformation (Russo et al, 1982; Anbazhagan and Gusterson, 1994). Studies assessing birth weight as a predictor of breast cancer have, however, reached different conclusions. The first large study was conducted in Sweden, using birth records, and showed a modest positive association between birth weight and breast cancer risk (Ekbom et al, 1992). In a second study that included birth record information from four additional hospitals, the same researchers could not confirm this result (Ekbom et al, 1997). Two other casecontrol studies in the US also showed no clear relation of birth weight with breast cancer (Le Marchand et al, 1988; Sanderson et al (1998)), although in one study a positive association for premenopausal women was suggested (Sanderson et al (1998). In contrast, a nested case-control study within the Nurses Health Study cohort found a positive association between birth weight and breast cancer risk (Michels et al, 1996). Most recently, one cohort study reported a weak positive association (Stavola et al,

*Correspondence: Dr L Vatten; E-mail: lars.vatten@medisin.ntnu.no Received 10 August 200 I; revised 6 October 200I; accepted I5 October 2001
2000), and the results of three case-control studies also showed positive but weak associations (Innes et al, 2000; Hübinette et al, 2001; Kajser et al, 2001).

In a review of the hypothesis that intrauterine exposures may affect adult breast cancer risk, Potischman and Troisi (1999) concluded that the question remains unresolved and that more studies are warranted. Since historical records of perinatal information are available in Scandinavian countries (Ekbom et al, 1992, 1997), we conducted a case-control study of breast cancer using birth records of two large hospitals in Norway. Our primary objective was to assess the association between birth size (i.e., weight and length) and breast cancer risk based on direct measurements obtained at birth. Using available information we could also adjust for potential confounding by the established risk factors of age at first birth and parity, which were not available in the Swedish data (Ekbom et al, 1992, 1997).

\section{MATERIALS AND METHODS}

The population base of this study comprised all female residents of Trondheim and Bergen, Norway, who were born at the two main hospitals in those cities between 1910 and 1970. In order to identify eligible participants, we first used the Norwegian Cancer Registry to identify 1035 breast cancer cases who were residents in these cities at the time of diagnosis. The Central Person Registry, a department of Statistics Norway, provided the necessary informa- 
tion to ascertain that 719 of these cases were also born in Trondheim or Bergen. This registry maintains continuously updated records on each woman's residential and childbearing history, including her mother's identity. For each case of breast cancer, we used the Central Person Registry to select four women $(n=2876)$ with no history of breast cancer. These potential controls were born consecutively to the case in the same city and were residents of Trondheim or Bergen at the time of the case's diagnosis.

In order to identify which cases and controls were born at the two main obstetric hospital departments in Trondheim and Bergen, we used the identity of the mother to locate the correct birth record files, since the mother was the index person in the birth record archives. For the 719 potential cases, birth records were identified for 187 in Trondheim, and 186 in Bergen. In Trondheim, we aimed at identifying four controls per case, and were able to find 669 (3.6 per case). Due to limited resources, we aimed at identifying three controls per case in Bergen, and found 481 controls (2.6 per case). Thus, birth records were identified for 1150 of the 2876 potential control women who were born at the two main hospitals (Table 1). The 373 cases were diagnosed between 1959 and 1997, with a mean age at diagnosis of 50 years (range $27-83$ years). The other women who were initially identified as potentially eligible for the study were either born at home or at smaller hospitals that are no longer in operation. Information from these sources has not been systematically stored, and was not used in the study.

From the available birth records, we abstracted perinatal information on birth weight (grams), birth length (centimetres), and placenta weight (grams). We also collected maternal information about height, marital status, and father's occupation; which was available for nearly half of the participants. The information on childbearing history (i.e., age at first birth, parity) of the cases and controls was collected from the Central Person Registry in Norway. We used conditional logistic regression to examine the effect of birth weight, length, and placenta weight on breast cancer risk, categorizing each study factor by quartiles, based on the distribution among controls, and making adjustment for age at first birth and parity.

\section{RESULTS}

As expected, increasing age at first birth was associated with increasing risk of breast cancer, and there was a reduction in risk with increasing parity (Table 2), and for birth order, there was no association. We found a positive association between birth weight and breast cancer risk (Table 2, $P$ for trend=0.02). Birth weight in the highest quartile $(\geqslant 3730 \mathrm{~g}$ ) was associated with an odds ratio of $1.4(95 \%$ confidence interval $=1.1-1.9)$ compared to the lowest quartile ( $\geqslant 3090 \mathrm{~g}$ ). For birth length, there was a

Table I Selected characteristics of breast cancer cases and controls

\begin{tabular}{lcc}
\hline Characteristic & Cases & Controls \\
\hline Year of birth $^{\mathrm{a}}$ & & \\
1910-1929 & $125(33.5)$ & $370(32.2)$ \\
1930-1949 & $205(55.0)$ & $634(55.1)$ \\
1950-1967 & $43(11.5)$ & $146(12.7)$ \\
City of birth $^{\mathrm{a}}$ & & \\
Trondheim $_{\text {Bergen }}$ & $187(50.1)$ & $669(58.2)$ \\
Birth weight (g) $_{\text {Placenta weight (g) }}{ }^{\mathrm{b}}$ & $186(49.9)$ & $481(41.8)$ \\
Birth length (cm) $^{\mathrm{b}}$ & $3443 \pm 520$ & $3389 \pm 505$ \\
Parity $^{\mathrm{b}}$ & $615 \pm 182$ & $614 \pm 188$ \\
Age at first birth (years) $^{\mathrm{b}}$ & $50.2 \pm 2.3$ & $50.0 \pm 2.2$ \\
& $2.2 \pm 1.2$ & $2.2 \pm 1.3$ \\
\hline
\end{tabular}

${ }^{a}$ Number and percentage of cases and controls; ${ }^{b}$ mean value \pm standard deviation for cases and controls.
Table 2 Odds ratios (ORs) and 95\% confidence intervals (Cls) of breast cancer associated with reproductive and perinatal variables ${ }^{a}$

\begin{tabular}{|c|c|c|c|c|}
\hline Variables & $\begin{array}{c}\text { Case } \\
\text { patients }\end{array}$ & $\begin{array}{l}\text { Control } \\
\text { subjects }\end{array}$ & OR & $95 \% \mathrm{Cl}$ \\
\hline \multicolumn{5}{|l|}{ Age at Ist birth } \\
\hline Nullipara & 28 & 130 & 0.9 & $0.5-1.6$ \\
\hline$<20$ & 24 & 101 & 1.0 & Reference \\
\hline $20-24$ & 130 & 459 & I.1 & $0.7-1.7$ \\
\hline $25-29$ & 123 & 313 & 1.5 & $0.9-2.3$ \\
\hline$\geqslant 30$ & 68 & 147 & 1.7 & $1.0-2.7$ \\
\hline & & \multicolumn{3}{|c|}{$P$ for trend $=0.003$} \\
\hline \multicolumn{5}{|l|}{ Parity } \\
\hline Nullipara & 28 & 130 & 0.6 & $0.4-0.9$ \\
\hline I & 70 & 173 & 1.0 & Reference \\
\hline 2 & 143 & 404 & 0.9 & $0.7-1.2$ \\
\hline 3 & 91 & 283 & 0.8 & $0.6-1.1$ \\
\hline$\geqslant 4$ & 41 & 159 & 0.7 & $0.5-1.1$ \\
\hline & & \multicolumn{3}{|c|}{$P$ for trend $=0.05$} \\
\hline \multicolumn{5}{|l|}{ Birth order } \\
\hline Para I & 164 & 471 & 1.0 & Reference \\
\hline Para II & 104 & 320 & 1.0 & $0.7-1.2$ \\
\hline Para III & 48 & 163 & 0.9 & $0.6-1.2$ \\
\hline$\geqslant$ Para IV & 54 & 186 & 0.9 & $0.6-1.2$ \\
\hline & & \multicolumn{3}{|c|}{$P$ for trend $=0.24$} \\
\hline \multicolumn{5}{|c|}{ Birth weight $(g)^{b}$} \\
\hline$<3090$ & 82 & 303 & 1.0 & Reference \\
\hline $3090-3410$ & 88 & 292 & I.1 & $0.8-1.5$ \\
\hline $3420-3720$ & 92 & 286 & 1.2 & $0.9-1.6$ \\
\hline$\geqslant 3730$ & || $\mid$ & 269 & 1.4 & $1.1-1.9$ \\
\hline & & \multicolumn{3}{|c|}{$P$ for trend $=0.02$} \\
\hline \multicolumn{5}{|c|}{ Birth length $(\mathrm{cm})^{b}$} \\
\hline$<50.0$ & 106 & 408 & 1.0 & Reference \\
\hline 50.0 & 100 & 309 & 1.2 & $0.9-1.6$ \\
\hline 51.0 & 73 & 170 & 1.5 & $||-.2 . \mid$ \\
\hline$\geqslant 51.5$ & 94 & 261 & 1.3 & $1.0-1.8$ \\
\hline & & \multicolumn{3}{|c|}{$P$ for trend $=0.02$} \\
\hline \multicolumn{5}{|c|}{ Placenta weight $(g)^{b}$} \\
\hline$<500$ & 81 & 228 & 1.0 & Reference \\
\hline $500-590$ & 58 & 162 & 1.0 & $0.7-1.4$ \\
\hline $600-700$ & 59 & 225 & 0.8 & $0.6-1.2$ \\
\hline \multirow[t]{2}{*}{$\geqslant 710$} & 69 & 195 & 1.1 & $0.7-1.5$ \\
\hline & & \multicolumn{3}{|c|}{$P$ for trend $=0.95$} \\
\hline
\end{tabular}

${ }^{a}$ Odds ratios are computed using conditional logistic regression with cases and controls matched on year of birth; ${ }^{b}$ odds ratios are adjusted for age at first birth and parity in the regression model.

similar positive association ( $P$ for trend $=0.02$ ), with an odds ratio of $1.3(95 \%$ confidence interval $=1.0-1.8)$, for the highest $(\geqslant 51.5 \mathrm{~cm})$ versus the lowest quartile $(<50 \mathrm{~cm})$. Adjustment for indicators of the mother's socio-economic status (i.e., maternal height, marital status, father's occupation) did not materially change these estimates in the subset of subjects for whom this information was available (data not shown). There was no association between placenta weight and breast cancer risk (Table 2).

\section{DISCUSSION}

Studies of the effect of birth weight on breast cancer risk have yielded different results (Le Marchand et al, 1988; Ekbom et al, 1992, 1997; Michels et al, 1996; Sanderson et al, 1998; Innes et al, 2000; Stavola et al, 2000; Hübinette et al, 2001; Kajser et al, 2001). The initial Swedish studies (Ekbom et al, 1992, 1997) employed a study design that was similar to that of the present study. However, a weakness of these studies was the lack of information on age at first birth and parity. Although information on these factors was available in the prospective Nurses Health Study (Michels et al, 1996) and could be adjusted for in the statistical analysis, recorded information on birth weight could not be retrieved from birth records. Instead, the mothers of the nurses provided this information, either from memory or from personal 
files. Major strengths of the present study were the availability of accurate measurements of birth size contained in the birth records as well as the ability to adjust for potential confounding by age at first birth and parity.

Birth length is typically measured by the half centimetre, resulting in a narrow variation compared to that of birth weight, which is measured in grams. Nonetheless, we found a positive association between birth length and breast cancer risk, and the strength of the association was fairly similar to the one related to birth weight. Previous studies with information on birth length have found only weak, and not statistically significant associations between birth length and breast cancer risk (Ekbom et al, 1992, 1997; Hübinette et al, 2001).

We found no evidence for any association between placenta weight and breast cancer. Previously, placenta weight has only been examined in the Swedish studies (Ekbom et al, 1992, 1997) that also found no association with breast cancer risk. In a separate study, however, the same research group reported a positive association between placenta weight and high risk mammographic patterns (Ekbom et al, 1995). There is a positive correlation between birth weight and placenta weight (Heinonen et al, 2001), and it is conceivable that an effect of birth weight on breast cancer risk could be mediated through pregnancy factors produced by the placenta.

\section{REFERENCES}

Anbazhagan R, Gusterson BA (1994) Prenatal factors may influence predisposition to breast cancer. Eur J Cancer 30A: 1-3

Ekbom A, Trichopoulos D, Adami HO, Hsieh CC, Lan SJ (1992) Evidence of prenatal influences on breast cancer. Lancet 340: 1015-1018

Ekbom A, Hsieh CC, Lipworth L, Adami HO, Trichopoulos D (1997) Intrauterine environment and breast cancer risk in women: a population-based study. J Natl Cancer Inst 89: 71-76

Ekbom A, Thurfjell E, Hsie C-C, Trichopoulos D, Adami H-O (1995) Perinatal characteristics and adult mammographic patterns. Int J Cancer 61: $177-180$

Heinonen S, Taipale P, Saarikoski S (2001) Weights of placentae from smallfor-gestational-age infants revisited. Placenta 22: 399-404

Hübinette A, Lichtenstein P, Ekbom A, Cnattingius S (2001) Birth characteristics and breast cancer risk: a study among like-sexed twins. Int $J$ Cancer 91: $248-251$

Innes K, Byers T, Schymura M (2000) Birth characteristics and subsequent risk for breast cancer in very young women. Am J Epidemiol 152: 1121-1128

Kajser M, Lichtenstein P, Granath F, Erlandsson G, Cnattingius S, Ekbom A (2001) In utero exposures and breast cancer: a study of opposite-sexed twins. J Natl Cancer Inst 93: 60-62
The positive association observed between birth size and breast cancer in the present study could be confounded by socio-economic factors. We did have some information that could indicate socio-economic differences, such as father's occupation, the mother's marital status at birth, and mother's height. The latter could also be correlated with the offspring's birth size for genetic reasons. Due to missing data on these factors for a substantial proportion of the participants we could not resolve this issue. Nonetheless, we did explore the potential confounding by these factors among participants for whom this information was available, but the main results were not substantially altered.

This study provides strong evidence that intrauterine factors may influence future risk of breast cancer. Since positive associations were found for birth weight and birth length, the relevant underlying factors would most likely be linked to fetal growth. A common feature of such factors would therefore be their ability to stimulate fetal growth and, simultaneously, to influence intrauterine development of the mammary gland.

\section{ACKNOWLEDGEMENTS}

This study was financed by NIH grant RO1 CA 78761.

Le Marchand L, Kolonel LN, Myers BC, Mi M-P (1988) Birth characteristics of premenopausal women with breast cancer. Br J Cancer 57: $437-439$

Michels K, Trichopoulos D, Robins JM, Rosner BA, Manson JE, Hunter DJ, Colditz GA, Hankinson SE, Speizer FE, Willett WC (1996) Birthweight as a risk factor for breast cancer. Lancet 348: $1542-1546$

Potischman N, Troisi R (1999) In-utero and early life exposures in relation to risk of breast. Cancer Causes Control 10: $561-573$

Russo J, Tay LK, Russo IH (1982) Differentiation of the mammary gland and susceptibility to carcinogenesis. Breast Cancer Res Treat 2: 5-73

Sanderson M, Williams MA, Malone KE, Stanford JL, Emanuel I, White E, Daling JR ((1998)) Perinatal factors risk of breast cancer. Br J Cancer 57: $437-439$

Stavola BL, Hardy R, Kuh D, Silva IS, Wadsworth M, Swerdlow AJ (2000) Birthweight, childhood growth and risk of breast cancer in a British cohort. Br J Cancer 83: $964-968$

Trichopoulos D (1990) Does breast cancer originate in utero? Lancet 335: $939-940$ 